\title{
A importância das metodologias ativas no aprendizado do Ensino Superior
}

\author{
The importance of active methodologies in the learning of Higher Education \\ La importancia de las metodologías activas en el aprendizaje de la Educación Superior
}

Recebido: 21/12/2021 | Revisado: 28/12/2021 | Aceito: 07/01/2022 | Publicado: 10/01/2022

\author{
Marcieli Borba do Nascimento \\ ORCID: https://orcid.org/0000-0002-8087-0801 \\ Universidade Estadual do Centro-Oeste, Brasil \\ Centro Universitário Campo Real, Brasil \\ E-mail: marcieli_bn@hotmail.com \\ Lucas Fagundes Santana \\ ORCID: https://orcid.org/0000-0001-8591-5637 \\ Centro Universitário Guairacá, Brasil \\ E-mail: lucasfagundes14@live.com \\ William Ferreira Rosa \\ ORCID: https://orcid.org/0000-0002-7797-9152 \\ Universidade Tecnológica Federal do Paraná, Brasil \\ E-mail: willcoach.saude@gmail.com \\ Matheus da Cunha Paris \\ ORCID: https://orcid.org/0000-0001-5373-1593 \\ Universidade Estadual do Centro-Oeste, Brasil \\ E-mail: matheusparis91@gmail.com \\ Katiuscia Francisco de Oliveira Gabriel \\ ORCID: https://orcid.org/0000-0002-6788-9938 \\ Universidade Estadual do Centro-Oeste, Brasil \\ E-mail: katiusciaofg@hotmail.com
}

\begin{abstract}
Resumo
Grandes mudanças sociais vêm acontecendo mundialmente com a globalização, a educação tem um papel fundamental em formar sujeitos críticos que saibam se colocar diante da sociedade e de suas mudanças, cientes de seus direitos e deveres. A partir da era da tecnologia e informação, as metodologias abordadas pelos docentes do ensino superior acabam sendo questionadas, já que seu papel é formar sujeitos ativos na sociedade. Diante desse contexto, a presente pesquisa tem a finalidade refletir sobre o uso das metodologias ativas no ensino superior, como é trabalhada pelos docentes e de que maneira, se a mesma facilita o processo de ensino aprendizagem. Trata-se de uma pesquisa qualitativa, realizada por meio da revisão bibliográfica. $\mathrm{O}$ desenvolvimento da presente pesquisa possibilitou uma análise sobre o uso das metodologias ativas Ensino Superior, partindo de uma reflexão acerca das mudanças na prática pedagógica ao longo dos tempos, também foi possível descrever como essas metodologias vem sendo utilizadas, destacando a importância da mesma no processo de ensino aprendizagem.
\end{abstract}

Palavras-chave: Metodologias Ativas; Aprendizagem significativa; Ensino superior.

\begin{abstract}
Great social changes are happening worldwide with globalization; education has a fundamental role in forming critical subjects who know how to put themselves before society and its changes, aware of their rights and duties. From the era of technology and information, the methodologies addressed by higher education teachers end up being questioned, since their role is to train active subjects in society. Given this context, the present research aims to reflect on the use of active methodologies in higher education, how it is worked by teachers and how, if it facilitates the process of teaching learning. This is a qualitative research, carried out through the bibliographic review. The development of the present research made possible an analysis on the use of active methodologies Higher Education, starting from a reflection on the changes in pedagogical practice throughout the time, it was also possible to describe how these methodologies have been used, highlighting the importance of the same in the process of teaching learning.
\end{abstract}

Keywords: Active methodologies; Meaningful learning; Higher education.

\section{Resumen}

Grandes cambios sociales se han venido sucediendo a nivel mundial con la globalización, la educación tiene un papel fundamental en la formación de sujetos críticos que sepan ponerse al frente de la sociedad y sus cambios, conscientes de sus derechos y deberes. Desde la era de la tecnología y la información, las metodologías que abordan los profesores de educación superior acaban siendo cuestionadas, ya que su función es formar sujetos activos en la sociedad. Ante este contexto, esta investigación tiene como objetivo reflexionar sobre el uso de metodologías activas en la educación 
superior, cómo la trabajan los docentes y cómo, si facilita, el proceso de enseñanza-aprendizaje. Se trata de una investigación cualitativa, realizada a través de una revisión de la literatura. El desarrollo de esta investigación permitió analizar el uso de metodologías activas en la Educación Superior, a partir de una reflexión sobre los cambios en la práctica pedagógica a lo largo del tiempo, también fue posible describir cómo se han utilizado estas metodologías, destacando su importancia en el proceso. de la enseñanza del aprendizaje.

Palabras clave: Metodologías activas; Aprendizaje significativo; Educacíon superior.

\section{Introdução}

Trabalhar com a educação no Ensino Superior constitui muitas vezes um desafio aos membros do corpo docente, pois os mesmos pontuam suas experiências, curiosidades, expectativas e necessidades aprendizagem diferenciadas, na expectativa de qualificar-se profissionalmente, visto que a formação superior nos dias de hoje vem constituindo ainda mais os objetivos de muitos jovens e adultos. Devemos considerar a globalização no mercado de trabalho que por ficar cada vez mais exigente e competitivo, requer mais e mais da sociedade (Da Silva Reis \& Pena, 2020).

Nesse caso as instituições de ensino superior juntamente com seu corpo docente devem refletir sobre o modelo de ensino que estão seguindo, buscar e desenvolver inovações metodológicas para que o processo de ensino aprendizagem se torne significativo e correspondam as expectativas desses acadêmicos.

O Brasil, conta com metodologias ativas mais utilizadas no ensino superior sendo: salas de aula invertidas e a chamada “peer instruction” a chamada "Revolução da Aprendizagem Ativa” (Mazur, 2015; Melo, 2017).

É impreterível que os docentes estejam sempre repensando as metodologias de ensino, pois, “o estudante precisa assumir um papel cada vez mais ativo, descondicionando-se da atitude de mero receptor de conteúdo, mas reestabelecendo efetivamente conhecimentos relevantes aos problemas e aos objetivos da aprendizagem" (Mitre et al., 2008; Melo, 2017). O uso das metodologias ativas tem sido apontado como abordagem que norteia a educação e permite que os alunos desenvolvam conhecimentos e habilidades relacionando outros saberes e habilidades às demandas sociais, políticas e econômicas (Pucinelli et al., 2021).

Assim sendo, as metodologias ativas possibilitam experiências novas aos alunos, o próprio aluno busca o novo, e isso contribui muito para a vida profissional dele porque trabalha a sua autonomia como também a sua capacidade para enfrentar desafios.

Neste sentido, o objetivo do presente estudo é nortear os docentes para um estudo de forma cientifica, ressaltando a importância das metodologias ativas no ensino; tendo como objetivo específico observar a importância das diversas metodologias no ensino teórico e prático.

\section{Metodologia}

O presente estudo se realizou por meio da pesquisa bibliográfica. A pesquisa bibliográfica é desenvolvida com base em material já elaborado, constituído principalmente de livros e artigos científicos. Embora quase todos os estudos sejam exigidos algum tipo de trabalho dessa natureza, há pesquisas desenvolvidas exclusivamente a partir de fontes bibliográficas (Gil, 2002).

O método escolhido para a pesquisa bibliográfica foi o qualitativo, que tem caráter exploratório e se utiliza do método indutivo:

Na pesquisa qualitativa, opta-se pelo método indutivo (dos dados para a teoria), por definições que envolvam o processo e nele se concretizam, pela intuição e criatividade durante o processo de pesquisa, por conceitos, que se explicitam via propriedades e relações, pela síntese holística e análise comparativa e por uma amostra pequena escolhida seletivamente (Gamboa \& Santos, 2007).

Após a escolha do tema, que é a primeira etapa da pesquisa bibliográfica, iniciou-se o levantamento bibliográfico 
preliminar. "Esse levantamento preliminar pode ser entendido com um estudo exploratório, posto que tenha finalidade de proporcionar familiaridade do aluno com a área de estudo no qual está interessado" (Gil, 2002).

Realizada a leitura exploratória, que é a fase de seleção do material, parte-se para a leitura analítica. Nesta etapa faz-se um estudo mais aprofundado dos textos selecionados, com a finalidade de ordenar e sumariar as informações que possibilitem a obtenção de respostas para a problemática da pesquisa (Gil, 2002).

\section{Resultados e Discussão}

\subsection{O Uso das Metodologias Ativas de Aprendizagem}

A metodologia da problematização é bem antiga e foi implementada nas áreas da saúde, pois a Aprendizagem Baseada em Problemas alavanca muitos objetivos educacionais, logo a maneira de aprendizagem desses profissionais torna-se significativa colocando o conteúdo teórico em prática. Embasados na problematização professores oferecem aos acadêmicos situações do cotidiano dos alunos e da sua área de estudo, sempre aliando a teoria à prática, o docente terá que desenvolver habilidades e competências para resolver o que foi proposto, sendo desafiado a procurar recursos, de maneira a experimentar e contextualizar a situação. Com essa experiência real, além da aprendizagem significativa que construiu, o mesmo também passa por experiências fatos e acontecimentos que poderá ser utilizada fora do ambiente de estudo.

Algumas universidades utilizam-se de alternativas metodológicas para a aprendizagem. Uma dessas alternativas é o Arco de Maguerez (Berbel, 1995):

Em 1982 Bordenave e Pereira seguindo a ideologia de Saviani, o qual segue a mesma linha de pensamento que Herbart e Dewey, o autor então descreve alguns passos que distinguem o modelo tradicional da educação voltada para a democracia.

Saviani descreve os seguintes passos: $1^{\circ}$ Passo: o ponto de partida A Prática Social Inicial, onde o conteúdo é contextualizado. $2^{\circ}$ Passo: Problematização, onde ocorre o questionamento do que precisa ser resolvido. $3^{\circ}$ Passo: Instrumentalização dos Sujeitos, onde ocorre o processo pedagógico. $4^{\circ}$ Passo: Catarse, onde o aluno demonstra uma nova postura diante do conteúdo estudado. $5^{\circ}$ Passo: Prática Social final, onde o aluno compreendeu a realidade e se posicionou diante dela. Com esses passos de Saviani, e forte influência de Freire foi possível para Bordenave e Pereira representar o Arco de Meguerez (Berbel, 1995).

Além do Brasil as metodologias ativas de aprendizagem, estão sendo utilizadas há muito tempo na área da saúde mais precisamente nos cursos de medicina, como curso precursor.

Aplicações das metodologias ativas tiveram início na década de 1960 com as escolas de McMaster no Canadá e Maastricht na Holanda. Sua difusão ocorreu nas escolas médicas dos Estados Unidos em 1985, em Harvard, Albuquerque, Havaí, bem como na África, Ásia e América Latina, sob a supervisão das duas escolas pioneiras (LOWRY, 1993). No Brasil, a Faculdade de Medicina de Marília (FAMEMA) em 1997, e a Universidade Estadual de Londrina (UEL) em 1998, foram às pioneiras (Millan, 2012). No estado do Rio de Janeiro, o primeiro curso a utilizar foi o da Fundação Educacional Serra dos Órgãos - FESO em 2005 (Mitre et al., 2008). Foi inicialmente introduzida no Brasil em currículos de Medicina, mas vem sendo experimentada também por outros cursos (Gomes, 2014).

Podemos perceber que por se tratar da união da teoria com a prática, torna-se significativo ao docente e esta inovação no ensino superior já demonstra que o método é eficaz e significativo ao docente.

O Ensino Superior é um desafio para o docente, pois o perfil do discente mudou, ele chega ao ensino superior motivado, com interesses, querendo aprender, encarando o conhecimento como um desafio sendo capaz de ir além (Silva et al., 2015).

Estes jovens fazem parte da geração Y, que nasceu em um mundo globalizado e dominado pela tecnologia. Outra característica importante desta geração é a intensa participação em redes sociais e o uso das mesmas para a socialização de 
informações e do conhecimento. Muitos já construíram formas de pensar e de aprender e chegam às universidades desafiando e criticando, diariamente, as estratégias pedagógicas utilizadas em sala de aula. Isto porque ser passivo e apenas ouvinte para esses estudantes é desmotivador, sendo possível em uma rápida busca na internet ter acesso a um universo de informações. As pedagogias centradas na transmissão do conhecimento não são adequadas aos educandos (Silva et al., 2015; Melo 2017).

Frente a isso algumas indagações surgem em relação às práticas de muitos professores universitários: Como tornar o aluno mais ativo? É vantajoso promover a autonomia desse aluno? Essas habilidades desenvolvidas serão bem-vindas?

Neste interim cabe ressaltar que: "Frente ao desafio de atuar numa nova visão do processo de ensino-aprendizagem, o docente poderá encontrar dificuldades que se iniciam pela própria compreensão da necessidade de ruptura com o tradicional" (Souza et al., 2014).

É necessário que se reflita sobre sua prática é uma necessidade do professor que vai atuar com jovens e adultos do Ensino Superior, neste sentido as metodologias ativas podem contribuir pela inovação em que aluno e professor constroem juntos os conhecimentos, deixando para trás práticas repetitivas e cansativas do passado.

Uma ciência do passado produz uma escola morta, dissociada da realidade, do mundo e da vida. Uma educação sem vida produz seres incompetentes, incapazes de pensar, construir e reconstruir conhecimento. Uma escola morta, voltada para uma educação do passado, produz indivíduos incapazes de se auto conhecerem, como fonte criadora e gestora de sua própria vida, como autores de sua própria história (Moraes, 1996).

É importante ter consciência e compreender as dificuldades e resistências que cada aluno demonstra em relação ao que foi proposto e buscar a melhor forma de realizar essa mediação. O professor deve estar atento os seus objetivos no processo de aprendizagem dos alunos, ele deve conhecer o perfil do aluno e planejar atividades, construir estratégias para que facilitem a construção do conhecimento.

Outra metodologia muito utilizada na aprendizagem ativa é a Taxonomia de Bloom revisada (Ferraz \& Belhot, 2010), a qual pode auxiliá-lo no processo de ensino aprendizagem a traçar e seguir seus objetivos, sempre avaliando e analisando o processo cognitivo dos alunos, para que o mesmo consiga de fato desenvolver suas habilidades e competências.

O "processo cognitivo pode ser entendido como o meio pelo qual o conhecimento é adquirido ou construído e usado para resolver problemas diários e eventuais" (Ferraz \& Belhot, 2010).

Dentro das metodologias ativas de aprendizagem podemos perceber as características da Taxonomia de Bloom, por estimular a autoaprendizagem e desenvolver a autonomia dos alunos. A qual envolve: o conhecimento cognitivo real assim como a consciência da aprendizagem individual. Essa subcategoria tem se tornado cada vez mais importante na área educacional uma vez que a possibilidade de autoaprendizagem e o controle do aprendizado relacionado à autonomia de aprender deve ser um processo cada vez mais consciente e passível de medição (Ferraz \& Belhot, 2010).

Desse modo é importante levar em consideração o perfil de cada aluno, a capacidade de aprendizagem de cada um, dentro das metodologias ativas esses domínios cognitivos são fundamentais para chegar ao objetivo desejado, sempre verificando o progresso do aluno, detectando se houve a aprendizagem ou há a necessidade de contextualizar novamente o conteúdo. Taxonomia de Bloom revisada divide em 6 categorias que vai da capacitação mais simples até a mais complexa dentro do processo de aprendizagem, que são:

1) Lembrar: que corresponde ao conhecimento adquirido pelo aluno, capacidade de processar e utilizar a informação de maneira significativa.

2) Entender: que corresponde a capacidade de o aluno interpretar de maneira particular o conteúdo que foi proposto pelo professor. 
3) Aplicar: onde o aluno pode utilizar de todo o conhecimento adquirido e ter a atitude de buscar recursos para resolver tal situação.

4) Analisar: onde o aluno consegue juntar tudo o que foi ensinado pensar sobre isso, organizando e assimilando tudo ao conteúdo estudado.

5) Sintetizar: nesse momento o aluno é capaz de discutir ideias, criar conceitos, ter argumentos relevantes, se mostrando crítico diante do assunto.

6) Criar: que corresponde em colocar em prática as habilidades desenvolvidas no processo de aprendizagem, reunindo tudo para criar algo novo 9 .

Não se preocupar apenas com coisas isoladas como, por exemplo, fixar apenas nos objetivos a serem alcançados, é importante que o professor incentive a capacitação cognitiva dos alunos, pois o processo de ensino aprendizagem abrange diferentes áreas além da cognitiva, socioeconômica, afetiva, política e cultural, é preciso pensar sobre isso e articulá-las, para desenvolver diferentes habilidades.

\subsection{A Metodologia proporcionando ao Professor o Repensar de suas práticas}

É importante repensar as metodologias, pois, "o estudante precisa assumir um papel cada vez mais ativo, descondicionando-se da atitude de mero receptor de conteúdo, buscando efetivamente conhecimentos relevantes aos problemas e aos objetivos da aprendizagem" (Mitre et al, 2008).

O docente deve posicionar-se como um estimulador, questionador, dando ênfase a aprendizagem do discente, e encaminhando seu conhecimento de senso comum para o conhecimento empírico, sempre ressaltando a importância do erro na construção da aprendizagem.

É importante que o professor desenvolva uma atitude de parceria e corresponsabilidade com os alunos, que planejam o curso junto, usando técnicas em sala de aula que facilitem a participação e considerando os alunos como adultos que podem se corresponsabilizar por seu período de formação profissional (Masetto, 2011). Nesse sentido podemos perceber a importância do docente abordar uma metodologia que envolva o grupo como um todo, onde o professor consiga usar as experiências dos discentes como uma fonte de aprendizagem, atuar como mediador na construção do conhecimento, pois o aluno deve sair capacitado para atuar na sociedade com sujeito de direitos e deveres. Neste contexto a relação da teoria e prática no ensino é muito importante.

Observa-se que prática e teoria no cotidiano escolar devem receber a mesma dosagem de atenção, tendo em vista o enriquecimento do trabalho escolar, uma vez que a teoria vem da indagação na busca de respostas que é respondida na prática, ou seja, a teoria é indissociável da prática, toda teoria surge de uma prática (Souza et al., 2014).

Ao discente é importante refletir sobre a realidade, pois a classe dominante não faz questão de que novos sujeitos críticos surjam para questioná-la como ressalta-se que "[...] a única forma de pensar certo do ponto de vista da dominação é não deixar que as massas pensem o que vale dizer: é não o pensar com elas.” (Freire, 1967).

Ou seja, é muito importante que uma instituição forme realmente sujeitos capazes de refletir sobre a sociedade, dispostos a detectar problemas, criar hipóteses para mudar a realidade.

Iniciativa criadora, curiosidade científica, espírito crítico reflexivo, capacidade para auto avaliação, cooperação para o trabalho em equipe, senso de responsabilidade, ética e sensibilidade na assistência são características fundamentais a serem desenvolvidas em seu perfil (Mitre et al., 2008).

Preparar os alunos para desafios futuros é uma tarefa importante da educação, visto que a realidade pode mudar neste contexto as metodologias ativas contribuem por basear-se no aprender a aprender. 
Considerando-se, ainda, que a graduação dura alguns anos, enquanto a atividade profissional pode permanecer por décadas e que os conhecimentos e competências vão se transformando velozmente, torna-se essencial pensar em uma metodologia para uma prática de educação libertadora, na formação de um profissional ativo e apto a aprender a aprender (Mitre et al., 2008).

As metodologias ativas de aprendizagem são apropriadas para o ensino superior, pois faz com que o discente possa enfrentar a realidade e buscar possíveis soluções para os problemas encontrados em seu cotidiano, atuando de uma forma crítica, reflexiva e criativa. Com essa atuação do aluno o processo de aprendizagem se torna mais significativo para o mesmo, já que ele deve construir o conhecimento, o docente deve pensar em proporcionar isso a ele ao planejar suas práticas. Da seguinte forma: “ $\mathrm{A}$ aprendizagem significativa é o processo pelo qual o aluno relaciona uma nova informação com um conhecimento existente, ocasionando em uma reflexão que modificará aquela informação, resultando em um novo conhecimento” (Souza et al., 2015).

As Metodologias Ativas baseiam-se nas formas de desenvolver o processo de aprender, utilizando experiências reais ou simuladas, visando às condições de solucionar, com sucesso, desafios advindos das atividades essenciais da prática social, em diferentes contextos (Berbel, 1995).

Quando o aluno se depara com um problema a partir da observação já vai buscando alternativas para a resolução. "O conceito de metodologias ativas se define como um processo interativo de conhecimento, análise, estudos, pesquisas e decisões individuais ou coletivas, com a finalidade de encontrar soluções para um problema" (Bastos, 2006).

A proposta das metodologias ativas é que o aluno desenvolva diversas habilidades durante o processo de ensino aprendizagem, por tratar de assuntos referentes ao cotidiano, a prática profissional e a sociedade. Por isso tais habilidades intelectuais, técnicas e comportamentais são tão importantes, a autonomia, criatividade, pensamento crítico-reflexivo, responsabilidade e liderança são algumas delas.

E que através delas o aluno consiga ter o conhecimento necessário e buscar recursos criar estratégias para resolver qualquer tipo de situação seja ela simples ou complexa, se mostrando cada vez mais competente.

Os princípios das metodologias ativas podem ser definidos como:

O que eu ouço, eu esqueço; O que eu ouço e vejo, eu me lembro; O que eu ouço, vejo e pergunto ou discuto, eu começo a compreender; O que eu ouço, vejo, discuto e faço, eu aprendo desenvolvendo conhecimento e habilidade; O que eu ensino para alguém, eu domino com maestria (grifos do autor) (Silberman, 1996).

Desse modo, podemos compreender que o aluno passivo, não tem condições de construir o conhecimento, ele apenas reproduz a ideia do professor. O maior objetivo da metodologia ativa é promover a mudança em sala de aula, mudança também na vida do aluno, para que o mesmo possa atuar de forma ativa na sociedade.

Por meio das metodologias ativas o desenvolvimento de suas habilidades, possibilitará ao aluno viver de modo integrado e efetivo na sociedade, e podendo enfrentar situações desafiantes. As metodologias ativas possibilitam experiências novas aos discentes, o próprio discente busca o novo, e isso contribui muito para a vida profissional dele porque trabalha a sua autonomia como também a sua capacidade para enfrentar desafios de forma individual e coletiva. Pois, o mesmo futuramente não sairá reproduzindo só o que lhe foi ensinado, mas terá o desenvolvimento de seus potenciais capacidades para aplicar em diversas situações da vida.

Não se trata mais de aprender a replicar as soluções dadas pelos professores aos problemas, mas de se preparar para novos desafios, problemas novos que exigem novos encaminhamentos e imaginação para soluções criativas (Masetto, 2011).

O aluno universitário contemporâneo em sua grande maioria é pesquisador, ele já traz consigo muito conhecimento, isso é um grande desafio para o professor, a aplicação das metodologias ativas de aprendizagem acredita no potencial desses alunos.

Atualmente a tecnologias estão muito presentes, e tem papel importante para "enriquecer ambientes de aprendizagem", 
nos quais o aluno pode construir o seu próprio conhecimento em interação com os recursos desse ambiente. Por isso, uma aula em ambiente informatizado é importante, pois é capaz de mudar o foco de ensino. Em vez de o docente repassar instruções, na aula ministrada em ambiente informatizado, os discentes buscam/constroem conhecimentos (Amaral \& Sabota, 2017).

As metodologias ativas de aprendizagem aparecem como recurso didático no Ensino Superior que o docente utiliza para desenvolver inúmeras habilidades no discente em diversas áreas de formação, como as habilidades intelectuais, de pensamento crítico, habilidades de raciocínio, habilidades de pensamento criativo, habilidades de pesquisa, entre outras (Berbel, 1995). Ao ministrar uma disciplina é dever do docente, descrever as habilidades e competências necessárias para alcançar o conteúdo.

As metodologias ativas têm por objetivo desenvolver habilidades no discente que possam servir de auxílio para que ele se transforme e consequentemente transforme sua realidade. Conforme. "As metodologias ativas estão alicerçadas em um princípio teórico significativo, a autonomia, algo explícito na invocação de Paulo Freire, numa perspectiva de transformação da realidade; afinal, conhecer é transformar" (Fernandes et al., 2005).

Outra questão importante dentro das metodologias ativas é promover ao discente a interação com o grupo, ou seja, o trabalho em equipe, isso possibilita conhecer novos conceitos/ideias sobre um mesmo assunto. Geralmente as atividades em grupos são formados apenas por pessoas que tem certa afinidade, com isso fica fácil de resolver um problema, pois todos acabam pensando de maneira parecida ou aceitam as ideias do líder do grupo.

E é necessário para a aprendizagem ativa que os grupos sejam heterogêneos ou de diversidade, que busca fazer a interação dos participantes e ao mesmo tempo retirá-los da zona de conforto gerando um conflito de ideias na busca do mesmo objetivo, promovendo novas experiências aos discentes.

Essa prática é bastante positiva de trabalho em equipe ou grupo, pois educa para que o aluno enquanto cidadão possa compreender melhor as outras pessoas, assim como desenvolve a comunicação por meio do diálogo. Também conhece os demais indivíduos, com a sua história e características, tradições, e a partir daí desenvolve capacidade para busca de novos projetos e soluções inteligentes sem conflitos (Maia \& Scheibel, 2001).

\section{Conclusão}

A aprendizagem significativa se dá por meio das experiências, participando ativamente do que foi proposto pelo professor, pois para que o aluno possa resolver algo ele deve desenvolver muitas habilidades ao mesmo tempo, é importante que os alunos se sintam desafiados, isso servirá de estimulo para que ele reflita, pesquise, se responsabilize pelo o que foi proposto.

Partindo dessa experiência com a problematização o aluno consegue compreender que a mudança é possível, desde que o sujeito tenha um pensamento crítico-reflexivo desse modo ele será capaz de mudar a si mesmo e também a sua realidade.

Desse modo, a aprendizagem significativa se consolida e quando o aluno em sua vida profissional se deparar com a realidade desafios/problemas, ele vai ter as experiências teóricas/práticas “do que fazer" e "como fazer," nesta situação, pois vivenciou/experimentou durante sua formação, reforçando a importância de colocar em prática os conteúdos abordados em sala de aula.

O maior objetivo da educação nos dias de hoje, é a formação integral dos alunos para o pleno exercício da cidadania, assim os aspectos de conhecimentos, habilidades, valores e atitudes culminam em uma aprendizagem significativa.

Por isso a importância do discente experienciar/vivenciar o que lhe foi proposto, para que o mesmo consiga desenvolver várias habilidades e competências ao mesmo tempo até chegar a resolução do problema, toda vez que o professor aproxima o conteúdo da pratica cotidiana faz com que o aluno seja ativo e crítico, colaborando para a sua formação integral e o tornando mais responsável. 
O desenvolvimento da presente pesquisa possibilitou uma análise sobre o uso das metodologias ativas Ensino Superior, partindo de uma reflexão acerca das mudanças na prática pedagógica ao longo dos tempos, também foi possível descrever como essa metodologia vem sendo utilizadas, destacando a importância da mesma no processo de ensino aprendizagem.

Diante das mudanças nas formas de ensino-aprendizagem, tanto discentes como docentes não aprendem somente dentro de uma instituição o ato de aprender perpassa além disso, de modo que é de extrema importância trazer o mesmo mais próximo possível da sua realidade, estar atento as necessidades dele, no contexto em que o mesmo inserido e trabalhar em cima disso para que ele consiga refletir, assimilar e de fato aprender sobre o assunto e ver que ele também é responsável pela mudança. Assim sugere-se que novas pesquisas sejam elaboradas, de forma a delinear as estratégias empregadas na condução da aprendizagem.

\section{Referências}

Amaral, P. D. F., \& Sabota, B. (2017). Powtoon: análise do aplicativo web e seu potencial mediador na aprendizagem. Revista Tecnologia e Sociedade, 13(28). https://doi.org/10.3895/rts.v13n28.4646

Bastos, C. C. Metodologias Ativas. (2006). Educação \& Medicina. http://educacaoemedicina.blogspot.com.br/2006/02/metodologias-ativas.html.

Berbel, N. A. N. (1995). Metodologia da Problematização: uma alternativa metodológica apropriada para o Ensino Superior. Semina: Cio Soc./Hum., v.16. n. 2., $9-19$

Da Silva Reis, M., \& Pena, N. (2020). Metodologias ativas como mediação pedagógica no ensino superior. Argumentos Pró-Educação, 5. https://doi.org/10.24280/10.24280/ape.v5.e557.

Fernandes, J. D., Xavier, I. d. M., Ceribelli, M. I. P. d. F., Bianco, M. H. C., Maeda, D., \& Rodrigues, M. V. d. C. (2005). Diretrizes curriculares e estratégias para implantação de uma nova proposta pedagogica. Revista da Escola de Enfermagem da USP, 39(4), 443-449. https://doi.org/10.1590/s0080-62342005000400011.

Ferraz, A. P. D. C. M., \& Belhot, R. V. (2010). Taxonomia de Bloom: revisão teórica e apresentação das adequações do instrumento para definição de objetivos instrucionais. Gestão \& Produção, 17(2), 421-431. https://doi.org/10.1590/s0104-530x2010000200015.

Freire, P. (1967). Educação como prática da liberdade. Paz e Terra.

Gamboa S. S., \& Santos Filho, J. C. (2007). Pesquisa Educacional: quantidade e qualidade. (6a ed.), Cortez.

Gil, A. C. (2002). Como elaborar Projetos de Pesquisa. Editora Atlas S.A.

Gomes, J. M. (2014). Trabalhando doenças sexualmente transmissíveis a partir de metodologias ativas de ensino.

Maia, C. M. \& Scheibel. M. F. (2009). Didática: Organização do trabalho pedagógico. IESDE Brasil. 20 p.

Masetto, M. T. (2011). Inovação na aula universitária: espaço de pesquisa, construção de conhecimento interdisciplinar, espaço de aprendizagem e tecnologias de comunicação. Perspectiva, 29(2), 597-620. https://doi.org/10.5007/2175-795x.2011v29n2p597.

Mazur, E. (2015). Peer Instruction: a revolução da aprendizagem ativa. Tradução: Anatólio Laschuk. Penso.

Melo, R. A. (2017). A Educação Superior E As Metodologias Ativas De Ensino-Aprendizagem: uma análise a partir da educação sociocomunitária. Americana, São Paulo.

Mitre, S. M., Siqueira-Batista, R., Girardi, M, J. M., \& Almeida B. M. C. (2008). Metodologias ativas de ensino-aprendizagem na formação profissional em saúde: debates atuais. Temas Livres Free Themes, 13(2), 2133-2144.

Moraes, M. C. (1996). O paradigma educacional emergente: implicações na formação do professor e na prática pedagógica. Em Aberto, Brasília, ano 16, n. 70, p. 57-69.

Pucinelli, R. H., Kassab, Y., \& Ramos, C. (2021). Metodologias Ativas No Ensino Superior: Uma Análise Bibliométrica / Active Methodologies In Higher Education: A Bibliometric Analysis. Brazilian Journal of Development, 7(2), 12495-12509. https://doi.org/10.34117/bjdv7n2-051.

Silberman, M. [PDF] Active Learning: 101 Strategies To Teach Any Subject. | Semantic Scholar. (n.d.). Semantic Scholar | AI-Powered Research Tool. https://www.semanticscholar.org/paper/Active-Learning:-101-Strategies-To-Teach-Any-Silberman/afdcc3e1c11a97b7a802f8606b0ccad1aef176f2

Silva, S. L. d., Silva, S. F. R. d., Santana, G. S. d. M., Nuto, S. d. A. S., Machado, M. d. F. A. S., Diniz, R. d. C. M., \& Sá, H. L. d. C. (2015). Estratégia Educacional Baseada em Problemas para Grandes Grupos: Relato de Experiência. Revista Brasileira de Educação Médica, 39(4), 607-613. https://doi.org/10.1590/1981-52712015v39n4e02312013.

Souza, C. D. S., Iglesias, A. G., \& Pazin-Filho, A. (2014). Estratégias inovadoras para métodos de ensino tradicionais - aspectos gerais. Medicina, 47(3), 284. https://doi.org/10.11606/issn.2176-7262.v47i3p284-292, 